\title{
Cognitive Cybernetics in the Foresight of Globalitarianism
}

\author{
Zdenko Balaž ${ }^{1}$, Krystian Wawrzynek ${ }^{2 *}$ \\ ${ }^{1}$ VERN University, Iblerov trg, Zagreb, 10000, Croatia \\ ${ }^{2}$ Zagreb University of Applied Sciences, Zagreb, 10000, Croatia
}

\section{A R T I C L E IN F O}

Article history:

Received: 23 April, 2020

Accepted: 07 October, 2020

Online: 24 November, 2020

\section{Keywords: \\ Cognitive \\ Cybernetics \\ Totalitarianism \\ Globalitarianism \\ Education \\ Captology}

\begin{abstract}
A B S T R A C T
This paper presents the results of the research conducted with the help of cognitive cybernetics about the "mass" factor from the theory of totalitarianism. According to the expert system model, "big data" analysis sought to discover knowledge for assessing the future status of digital social connectivity. Originally developed models and methods of cognitive and computer research and processing of "eminent text" with the help of "convolution" from the theoretical background of many works about the past totalitarianism, recognize the same characteristics of emerging globalitarianism. Using search correlation, algorithms have confirmed a suspicion that intelligent interactive technologies impact the changes of the human psychophysical structure, through the digital social network of globalitarianism. Applying new intelligent interactive technologies without being familiar with their deeper impact, could plausibly make people accept them as part of themselves. People's digital obsession with the internet in a "global village", is increasingly similar to blind obedience, of the sympathizers and followers, gathered around past totalitarianism's grand leaders. There is a visible correlation between such technological-integration engagement, and the loss of social intelligence, leading to a conclusion that the future interactions between people and intelligent technologies will turn the history into the implosion of current events. History today is already pretty accelerated, due to its own mass digital integration and interaction, turning it into an illusion. There is a danger that globalitarianism, as an elusive end of the history, will escape cyclical times, due to unavoidable repetitiveness.
\end{abstract}

\section{Introduction}

According to the above-mentioned sample literature, Žarko Paić's book: "The talk about totalitarianism can never be neutral nor objective, like talking about something that forever belongs to the distant past. Man in his historical being is a creature of the existential sense of responsibility and also has his endless mission. What's left, in the end, is a radical settling of accounts with the possibilities that the past as a traumatic event constantly defines our future with a sense of guilt and responsibility. By taking over the legacy of the past something much bigger than just an unconditional ethical obligation is also taken along. This is the last lesson in which this world is becoming a place for searching the truth without fear of the consequences. And that's the only thing that makes sense. And therefore is the hardest."

\footnotetext{
"Corresponding Author: Krystian Wawrzynek, krystian.wawrzynek@gmail.com
}

Based on the principles of cognitive cybernetics, searching for truth could start by creating a system of history placed in timespace, in which from today's perception humans' integral actions are used for the purpose of technology. The first step for that system is to define time and its thinking models, and later to begin with cybernetic observation. Hannah Arendt, in her book (selected sample literature...), points out how being a human and being free, (the event of liberty- lat. constitutio libertatis), is the one and the same thing. A human being is the only creature in the world capable of initializing an action which could trigger a change characterized by unpredictability, uniqueness, and singularity of its activity.

In globalitarianism, these characteristics are lost, and as such, in this world of actions, are inevitably and unnecessarily subsided into the transformation of the events into the life itself. Through globalization, a man is brought into a state presented to him as a limit of his existence, and while venturing into modern technology 
projects, and without the ability to think for himself, he doesn't even realize he is not free. In this digital sociability, people could become followers of an unknown leader, who gains their obedience due to being unnoticeably lured. Revealing a lack of freedom is managed by the help of cognitivistic and cybernetic interoperability, in processing thematic contents.

\section{Historical activities}

From the Cybernetics point of view, history as a system of actions aspires towards a contingency of events, which in historical aspect means that it strives towards stability. Civilization as a system, when it is coming closer to a perfect operationalization, is on the brink of its breakdown. Observing history in space as a real factor in which it is happening, and in time as an abstract factor, an event happening in running time finds itself in a void between history and future, presenting a mindboggling reality that new information is already outdated. Sensory experience in space/time within which it "instantly happens", as a "situational psychology" in "position grouping", "is the essence of sustainability in the encounter as a constellation" [1-4].

The effect of today's intelligent technology is so strong that the continuity of today's historical era is becoming inhumane machinery. Authors of the selected representative writings [5-6], on historical example of totalitarianism, point out that a man through right activities can take control of what is not allowed and what is needed to be done. The criteria for doing good are selflessness and thoughtfulness which could produce positive indications in behavior towards others. Common sense is not common to everybody, but it helps people to fit into a community and allows them to communicate in situations expressed by senses. Common sense judgments are community judgments, where the sound mind is the only sense capable to act. Capability and possibility of human (no)actions are disclosed in this paper by cognitive cybernetics, as something past and terrible (totalitarianism), but also as potentially dangerous still to come (globalitarianism). Figure 1.

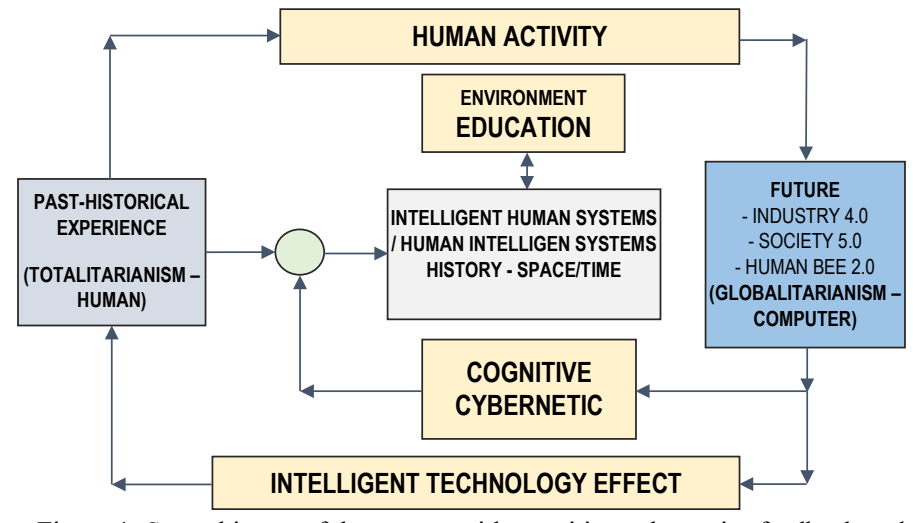

Figure 1: Space history of the system with cognitive cybernetics feedback and efficiency of human and intelligent technologies

For a human activity, which could be mental or physical, one needs a will which must be free and reasonable, otherwise, it wouldn't exist. Free will behaviour is able to identify itself with a command, but also with predictable unpleasant feelings of force and self-deception. With a lack of will, self-deception stops surpassing the feelings, in order to achieve a command. Therefore while searching for answers about history's time, it would be useful to search for them in its historical experiences but also in predictions of its future.

It is noticed that history's time is slowed down by indifference and amazement and those are the exact parameters of the historical activity that the cognitive cybernetics which also confirms its importance in globalitarism, and which has been precisely discussed in the literature [7-8].

\subsection{Time}

Based on a philosophical perception of historical experience, (Fink, Gadamer, Paić, Wilber, Husserle,...), time (lat. tempus) stands for a way and a flow. According to Plato, it is a motion picture of eternity, and a factor of all changes in the world, and every change happens suddenly (gr. $\varepsilon \xi \alpha \varphi v i \kappa o ́ \tau \eta \tau \alpha)$ when one form transforms into another. The link between time and unexpectedness is amazement, which for an instant turns into an ecstasy, represented in the word "now". If time is authentic, then it gets a sense of being, from its truth in the original time and belongs to the topology of the being. Historical time makes sense in narrating factual events, while primal or original time, i.e. prehistoric (gr.- $\alpha \rho \chi \imath \kappa \alpha)$, is lost as soon as it is brought down to a level of "just now". A paradox of time as repetition is a pseudo synthesis of the past and the future, like "eternal occurrence" of the exact same thing that is presumably objective necessity for freedom of actions. The chronological sense of time calculated by a clock is a measurement for living a human life. The time paradox is the objective time in a technical sense, which is eternal present and eternal future, and infinity and eternity. Generally, time's metaphysical structure is an everyday life present in relation to the time essence, and zone of infinity and temporality, as well as a linear cyclical flow of events as existence. Time's psychological structure raises the "self" from the abyss to the highest spheres of being and existence, in the form of life's creative potential [9-11].

Time as a meeting event and a mediation medium occur in possessive attitude towards things, and as temporality, it is an original, existential, hermeneutic phenomenon of engagement in the reconstruction of fundamental issues of time and being. Time as an abyss of freedom is not astronomical nor calendar, because it is unlimited in a sense that even now is a limitless line of dots. Time understood as an ability to act in a certain date in time, marked using time measurements based on important world's events, is stretched between carefully securing a passing of the present while awaiting a transformation of the past, which is far from a simple flow of equal time segments. That is the future that under no circumstances should bet the destruction of history. Time must not be a moment of anything but freedom, to act based on non-exclusivity, discovery, and validation, which are foundations for cybernetic observation and realization, bringing us to a conclusion that time must not ever become virtual [12].

\subsection{Cognitive cybernetics}

Cognitive cybernetics is a new scientific discipline based on foundation of cognitive sciences and cognition as a human mental potential, that connects cybernetic understanding of everything as a system (technical, social, natural...), with the new intelligent 
technologies that by cognition of interactions could point out to captologic anthropomorphosis of present-day human [13-15].

Based on available sources of information, today's science is becoming more and more empirical science about a man and everything that could become his personal technical experience achieved through new technologies. With its help, a human is placed in the world that adequately processes multiple productions. All that is accomplished everywhere based on and in the interest of scientific development of certain human capacity determined and lead by new cybernetics [16-18]. It determines a human as a social-working being and it is a theory that covers the possibility of planning and organizing human work. The language of cybernetics is transformed into a news exchange medium by which the whole world and a human's place in it, is determined and controlled. It is important to respond cognitively because only human engagement which must be thoughtful (thought, will, reasoning - cognition as human energy) and productive (working, producing and acting), can ensure the effect of unbiassed power of freedom. Based on that, two terms introduced from the totalitarianism, represent a foundation on which lies a hypothesis that identifies the meaning of the two globalitarianism's factors which are observed through a prism of today's digital social connectivity: (1) Latent structure of mass conscience; and (2) Permanent terror of irrational rationality. The results of previous research processed in published papers, [12-18] confirm the possibility of implementation in other areas. Considering that a way/goal of an action is much more important than any conscience manipulation, the modern ideology of mass digital society directs attention into the virtual reality which appears as a cultural totalitarian reality [19-23].

\section{Globalitarianism as a system}

In all totalitarian regimes, morality collapsed and became a mere habit and a custom with catastrophic consequences. Those who were the culprits of totalitarianism and those who remained quiet and accepted the situation, although they had an opportunity to speak up, but chose not to, are equally responsible. Moral behavior is not understood by itself, because a man is influenced by an example. And he reacts based on his own judgments. Using the new intelligent and interactive technologies in digital social networking, a human becomes less and less responsible towards himself. If he lost self-respect and started to despise himself, he wouldn't be able to act in his own interest and towards his own self-improvement anymore, and therefore he would not be able to take care of others.

If global is observed as a system (lat. globalus), which relates to the whole planet, with stress on absolutely strict centralistic and birocratic unity as unitarism (lat. unitus), then acronym is globalitarianism.

The ideology of intelligent technologies in today's digital society is becoming the means/purpose of a regime and it will cause much worse things then brutality of terror because the historical memories are fading away. Digital social connectivity created by intelligent technologies is close to a violence policracy. That Lars Rensmann's term is connected to a totalitarian state as a pluralistic non-state and paradoxically to self-understanding of everything that doesn't have an analogy in history. A problem occurs when every system (economic, political, cultural) is observed as totally rational and technically perfect, and states as communities of the global world organize the entire life of their citizens and depoliticize members of the birocratic management machine. The modern societies have become mass machinery of consumption fabrication. Technology and science together with a mass consumption culture make those societies dehumanized production plant which is going to use the system of globalitarianism as a process.

\subsection{Modeling}

When using a search algorithm to select dominant axioms from the Glasser's Choice Theory (CT) which is described by 10 axioms [24], then they could be presented as "Model 4P" where 4Ps are: need, action, behavior, and acceptance (cro. potreba, pokretanje, ponašanje, prihvaćanje). The model could also be applied to an evolved captological "3P" model, where 3Ps are: persuasive, permissive, and pervasive.

In "3P" model persuasive is captological, (Captology = Computer As Persuasive Technology), and that is presented through the Hermeneutic circle where the Choice Theory will be complemented by four Wilber's modernity quadrants. The circle would consist of a sequence of information, control, time, and freedom. A coincidence between the Hermeneutical circle from the Choice Theory [24], and the level of Wilber's halons [25], where I, "ME" stands for intentional, "WE" for cultural, "THIS" for social and "THAT" for behavioral, is integrated in a role of persuasiveness in totalitarianism, which model will be used to provide adequate parameters in Figure 2.

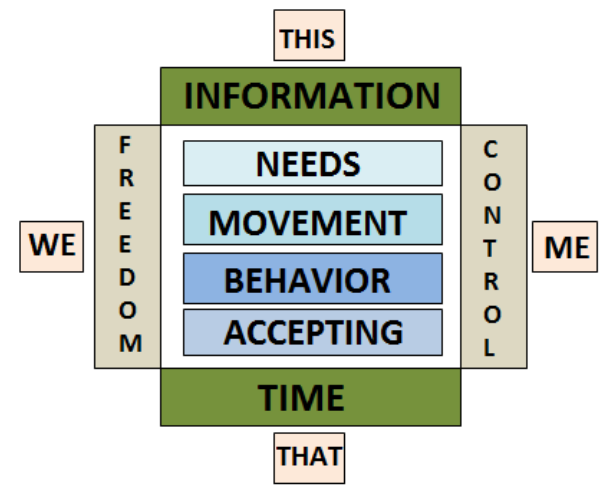

Figure 2: The dominant axioms of Glasser's Theory of Choice and Wilber's modernity for the treatment of totalitarianism with cognitive cybernetics

Processing with the help of the cognitive and cybernetic interoperability is based on the technical possibilities of the practical search system with adapted communication which are basically:

Syntactic: because they allow systems to communicate and exchange data in specific formats and communication protocols (XML; SQL standards, ASCII formats, including lower format levels of alphabetic signs). Letters treated as a multi-referential sign point out to the order, which is related to the alphabet syntax, and is different from one manifested, and follows the combinations and permutations logic, which in a word and a text display crypto semantic traces, and acquire a visual profile in their interpretation and shape. That way their construction, while inscribed in the order of meaning, determines the literal manifestation of the analyzed text that carries a specific meaning. Storing it into a database provides a memory which preserves the 
media, communication, transparency, and uniqueness of the characters. The letters are given the power to repeat in memory what has previously been established, guaranteed and unquestioned.

Semantic: as it allows for automated and meaningful interpretation of exchanged data for accurate formatting of results. The final use of the exchanged information of all involved parties is enabled by a reference model. The exchanged content is unambiguously defined by the original template PETAP, (hrv. Pomoćni Eminentni Tekst Aplikativne Paradigme) [23-30]. That template as its name suggests is "eminent text" that: a) serves for a presentation of the fixed sense; b) opens / reveals possibilities for understanding; c) cannot be predicted in advance; and d) has a character of actuality. The actuality emerges as an example of a probable occurrence of reality, as created in cognitive processing by reading and thinking by which a fixed experience of understanding is gained. That way presenting of the fixed thought content means "the presence of an existing" which could objectively meet the normative requirement. It is the same product that is repeatedly appearing in the search stages focusing on it in order to achieve verified meaning and understanding. The fixed content is conditioned and limited by the same thing, and when it was saved (without an ability to escape), that condition modeled on the hermeneutical approach becomes cognitive learning of its own character manifestation saved through technical and general functional forms. Superior cognitive interoperability refers to the cognitive collaboration of different systems, individuals and organizations which besides technical systems cognitive engineering is also taking into consideration social, political, organizational, chronological, biological, psychological and plausible factors. The processing modeled on computer metaphors and terminology is at the end completed with the original algorithmic model MOKSA (hrv. Model Opservacije Konvolucijsko Separacijskom Analogijom). According to this model, a mathematical function of convolution with all its characteristics of linearity, commutativity, and associativity is calculated similarly to correlation by mirroring one of the functions [31].

The application of the search and processing tools based on the expert system principle results in the available databases and knowledge bases. Searches that begin by analyzing and specifying requirements for knowledge bases and databases with welldefined need are crossing over into creating applications attempting a search using the learning agents' experience. An action initially begins in an unknown environment, so learning elements are used in the search process and the performance elements are formed by the evaluator and task generator. As the search gains more knowledge, the action becomes better and safer. The Data Collection Model has enabled upgrading in accordance with the acquired knowledge and needs, which were also empirically enabled by using relations and user forms in inputting and reviewing databases and formatting reports. Presenting and fulfilling the sense of the search is close to the cybernetic forensics and a base for presented understanding, which is fulfilled over the time, therefore searching and processing is to be completed by the cognitive synthesis and by reinforcing the concluding expertise.

\subsection{Role of Persuasion}

Persuasion (lat. persuasio) is connected to a form of communication seeking to influence judgments, attitudes, beliefs, or actions of an individual. As part of the persuasion acronym captology (lat. Persuasibilibus = lured), refers to being lured by the intelligent interactive computer technologies which also represents the form of communication. A form of communication that conveys information through the media represents propaganda. Extensive researches reveal that some forms of propaganda serve to inform, to persuade or in some more complicated synesthetic way to occupy human life in order to draw attention. The word propaganda dates from 1626 when a Christian community Sacra congregatio Christiano nomini propaganda has appeared, founded with the purpose of expanding Catholicism and regulating church relations in non-Catholic countries. More recently, since 1920, it has been used as methods of broad political industrial consciousness and a way of articulating ideological field of action although it is not an ideology itself. Propaganda linked to the development of technical (new) media, for which it has been proven to serve as a massive manipulation of feelings and attitudes.

This fact was disclosed in 2000 based on the research carried out by Manstead, Fischer, Kardum, and Larsen [32]. By setting up a mood control system, described by the cognitive cybernetic system, Larsen found that personality is a dynamic system within an individual which by its psychophysical parameters can adapt to a specific environment, and can also be affected by the environment. Every current state of the individual is his current mood, which Larsen found is modeled after potential mechanisms of individual differences that are in fact his mood regulators. An individual pursuit to achieve and maintain a good and comfortable mood and a positive attitude include the existence of negative feedback in the regulation model. Any action to reduce a difference appearing in the disadvantage of the good mood could be influenced by the strong cultural matrix in which the medium acts, and which could contain the immediate environment disturbances. This is particularly apparent in the totalitarianism where the masses believe in a new culture of organized lies. The problem is a double morality due to the personality philistine profile dominating in such an environment. Additionally the destruction of people's privacy and personal moral continually redefines individual identities imposed by the society as an escape from the social identification. Recruiting from such a mass of seemingly uninterested people, who many consider too apathetic and have already given up on them, allows for an introduction of completely new methods in propaganda and for ignoring of adversary arguments.

The future model as a system functions based on an assumption that the desired mood is to be achieved by comparing the current mood with the one to be achieved, and could be misleading because of not recognizing the desired state due to strong influence of Parameters, (Pi), Mechanisms, (Mi) and Strategies $(\mathrm{Si})$.

The strength of the media is exactly in its appearing as affectively relevant environment, which is confirmed by McLuhan's 1960's anthropological technological determinism [33] in Figure 3. 


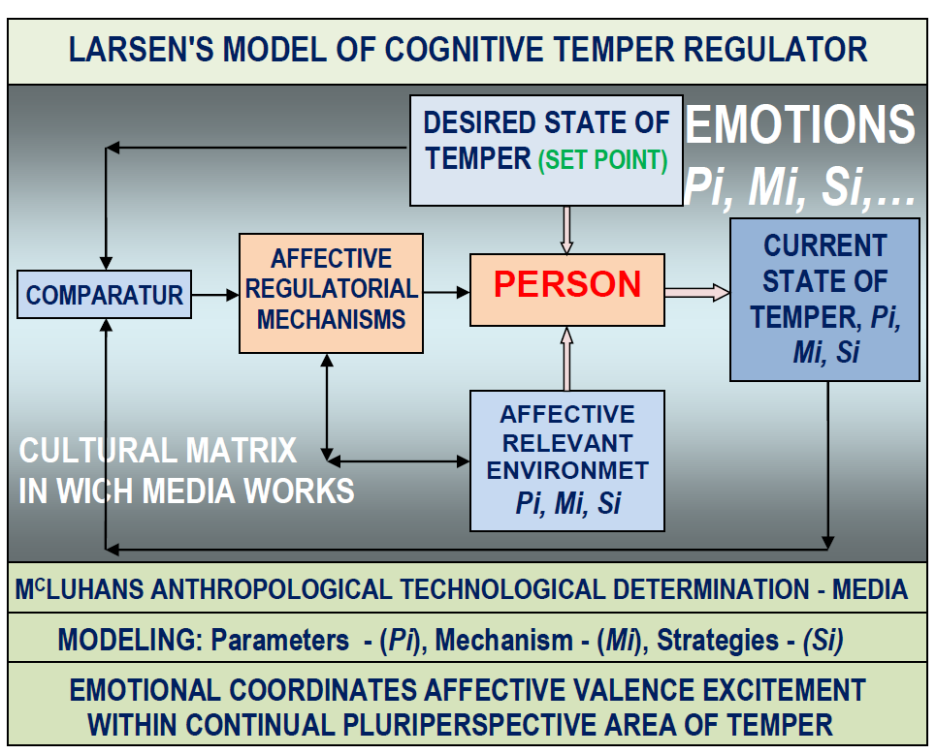

Figure 3: Model of cognitive temper regulation by Larsen and McLuhan's anthropological technological determinism

\subsection{Mass Man's Parameters}

The early 19th century's predictions pointing to the emerging of a mass man and the arrival of a mass era came true in the twentieth century. Besides the psychology of the European mass man, the profile of the mass man, gained increased importance, by unexpected and unpredictable phenomena such as:

- a radical loss of personal interest in everything that surrounds him,

- cynical and decadent indifference when encountering disasters or other personal catastrophes and even the death itself,

- the passionate tendency towards the most abstract concepts as life ideals,

- general disgust towards any events,

- loss of criteria even towards the most obvious rules of common sense.

Such an apathy, as a feature of totalitarianism, is today's plague called anhedonia. Search implementation based on the results of the modern analytical ontology is successful primarily because of the theory of general categories, which uses a data format to also present a concept. The formats/concepts that are used are for example person, personality, event, and event as a happening. The transition from a possibility to reality is an ontology of real events for which ontological research expands even to the relationships that people have with each other.

Therefore the conceptual modeling has encompassed characteristics determination of the presence of space and time using a classic relational model, whose basic concepts are structure, constraints and set of operations.

All existing real foundations from the early thirties of the past century are attributes of today's virtual realities that are rapidly streaming towards globalitarianism. The research-based premises have proven to be identical principles of establishing a framework for sustainability and goals of totalitarianism and globalitarianism in Figure 4.

\section{TOTALITARISM}

LEADER / initiator

PARTY / nebulizer

TOTALNARIAN STATE -

MASS followers, supporters

PROPAGANDA

\section{GLOBALITARISM}

INTERNET / initiator

SIMULAKRUM / nebulizer

"GLOBAL VILLAGE" -

MASS followers, supporters

\section{PERSUASION}

\section{IDENTICAL PRINCIPALS OF ESTABLISHED FRAMEWORK}

FASCINATION - as a social phenomenon

FANATISM - overly fascinated socjety

IDEALISM - experiences of created community

SOCIAL MOVEMENT FRAMEWORK - followers, identification

CONFORMITY - modern opinion chaos

\section{IDENTICAL RESILIENCE FACTORS}

- lack of critical thought

- unyielding persistence

- videospread convictions

- true followers unselfishness

- exceeding every real experience

- cancelling every immediate personal interest

- increasing apologetic - nostalgic approach

- increasing psychological - nostalgic attitude

- modern opinion chaos

- general condemning of moral norms

- crown mentality

IDENTICAL GOALS

- SUPERFICIAL DEPOLITIZATION AND NEUTRALIZATION OF POLITICS

- LATENT STRUCTURE OF MASS CONSCIOUSNESS MANIPULATION

- MODERN IDEOLOGY OF MASS SOCIETY WITH TARGETED ATTENTION

- SOCIETY AS A TOTAL MONITORED GROUP FOUNDED ON WORK AND TECHNICS

Figure 4: Comparison of totalitarianism and globalitarianism considering establishment premise, sustainability and goals

Instead of asking a question whether the ideology of terror, control, totalitarianism, etc., has a chance in the future, the successful search has proved that the "man of the mass" has, in fact, a problem of losing the social intelligence and functional connectivity due to technological integration. In the example of the ontological creation of the concept of persons, personalities, and events, the comparative studies of Buyse and Larsen, 1979 and Dunbar and Spores, 1995, confirm the structure of a man as a social being created through contact at the expense of social intelligence. Described examples of totalitarianism confirm that policies were consciously developed by a steadily increasing number of sympathizers with the controlled number of movement 
members (parties). Totalitarianism's theoretical background modeling today's digital social connectivity (3SC), (hrv. današnja društveno digitalna sprega -3DS) has confirmed these premises.

\section{Conclusion}

The real function of the totalitarian matrix is the ingeniously finding members' illusion towards sympathizers. Actually, the movement has carefully recruited its members by establishing an internal gradual hierarchy in order to avoid indoctrination. The outside world viewed as "normal", considers sympathizers as innocent fellow citizens in the non- totalitarian society. In that formation an anonymity greatly contributes to the unusual phenomenon of the mass easily manipulated, because of being too lazy or not brave enough, and always under the pressure of constant "moving", because it is known that the movement has no plan, but as the word itself says, "must move".

The problem is multiplied by the fact that today's digital social connectivity became imperative in creating curricula, plans, and strategies of modern education. There are very few studies which could differentiate the effectiveness of this novelty, and even less professional and scientific reviews of verified problems $[34,35]$.

On the contrary, today's digital social connectivity has negative effects on the younger population whom it deprives of very much needed mental creativity [36, 37]. It has been emphasized in the introduction that the temporality of history has been slowed down by indifference and astonishment, which are some of the selected parameters studied by cognitive cybernetics, in revealing the man of the mass globalitarianism $[38,39]$. This problem repeatedly occurs in philosophical reflections and futuristic predictions [40]. Statistical data collected for the Big Data model through historical and current reality as results of the research conducted with the help of cognitive cybernetics about the "mass" factor from the theory of totalitarianism are the subject of processing for the next scientific paper. Using search correlation, models and algorithms have confirmed a suspicion that intelligent interactive technologies impact the changes of the human psychophysical structure, through the digital social network of globalitarianism.

\section{Conflict of Interest and Funding}

No conflict of interest was reported by the authors. This work was supported by the AEROING d.o.o. Zagreb, Croatia, Europe and ELOS d.o.o. Split, Croatia, Europe as the partners and cofounders of the Institute for Cognitive Cybernetics Eastern Europe, Zagreb, Croatia.

\section{Thanks}

Special thanks to Mrs. Marijana Agičić (Saamis Immigration Services Association, 659-3rd Street, Medicine Hat, AlbertaCanada) who carefully read this paper and contributed to her advice and editing in English.

\section{References}

[1] U.V Detlev, Psychologie und Welt, W. Kohlhammer, 1972.

[2] M. Cipra, Temelji ontologije, Tehnički centar NZMH, 2003.

[3] C. Duhigg, Moć navike Zašto činimo što činimo i kako se promijeniti, Mozaik knjiga, 2013.

[4] G. Figal, Der Sinn des Verstehens, Beiträge zur hermeneutischen Philosophie, Philipp Reclam, 1996.
[5] Ž. Paić, Totalitarizam?, Meandarmedia, 2015.

[6] H. Arendt, Izvori totalitarizma, Kikagraf, 2015.

[7] Z. Balaž, K. Meštrović, Politehnička kognitivna kibernetika, Manualia Polytechnici Studiorum Zagrabiensis, 2018.

[8] Z. Balaž, M. M. Ninčević, Kognitivna kibernetika, Računska racionalnost misaonih sustava, GK, 2019.

[9] M. Heidegger, Ontology (Hermeneutics and Factuality), Bröcker-Oltmanns, 1988.

[10] H. G. Gadamer, The Legacy of Europe, Parnas, Press, Targa, 1997.

[11] Ž. Paić, Sfere egzistencije: Tri studje o Kierkegaardu, Matica Hrvatska, 2017.

[12] Z. Balaž, "Integration of Cognitive Cybernetics into Intelligent Human Systems?", $1^{\text {st }}$ International Conference on Intelligent Human System Integration, 2018.

[13] Z. Balaž, "Brain - A Flexible Self-Adaptive Entity", Public lecture and workshop conducted on $13^{\text {th }}$ Brain week in Croatia, at Electrical department of Zagreb University of Applied Sciences, 2014.

[14] Z. Balaž, "Brain - Communication Through Rhetoric and Artificial Intelligence", Public lecture and workshop conducted on $14^{\text {th }}$ Brain week in Croatia, at Electrical department of Zagreb University of Applied Sciences, 2015.

[15] Z. Balaž, Brain - "Cooperation or Bidding with Intelligent Systems", Public lecture and workshop conducted on $15^{\text {th }}$ Brain week in Croatia, at Electrical department of Zagreb University of Applied Sciences, 2016.

[16] Z. Balaž, "The Brain lost in the space of persuasive no-placelessness", Public lecture and workshop conducted on $16^{\text {th }}$ Brain week in Croatia, at Electrical department of Zagreb University of Applied Sciences, 2017.

[17] Z. Balaž, "Brain - Part of cognitive cibernetics against artificial intelligence", Public lecture and workshop conducted on $17^{\text {th }}$ Brain week in Croatia, at Electrical department of Zagreb University of Applied Sciences, 2018.

[18] Z. Balaž, "Brain - Cognitive cibernetics against digital demention", Public lecture and workshop conducted on $18^{\text {th }}$ Brain week in Croatia, at Electrical department of Zagreb University of Applied Sciences, 2019.

[19] M. Heidegger, Kraj filozofije i zadaća mišljenja, Rasprave i članci, Filozofska biblioteka, 1996.

[20] Z. Balaž, "Cognitive Cybernetics - a Future Society 5.0", International Symposium P\&P, 2017.

[21] Z. Balaž, M. Haun, "Cognitive Cybernetics - A Future that is Started", $34^{\text {th }}$ International Symposium on New Technologies, 2017.

[22] Z. Balaž, B.-I. Balaž, Human Computer Interaction, Cognitive Cybernetic \& Captological Education, Whioce Publishing Pte. Ltd., 2018.

[23] Z. Balaž, S. Desin, "Kognitivna kibernetika i globaritarizam", 38 Munarodni elektroinženjerski simpozij, EIS 2019- Dani Josipa Lončara, 2019.

[24] W. Glasser, Choice theory: a new psychology of personal freedom, Alinea, 2000.

[25] K. Wilber, A Theory of Everything, Gorin, 2004.

[26] E. Fink, Einleitung in die Philosophie, Franz-A. Schwarz, 1985.

[27] Ž. Paić, Sloboda bez moći, Politika u mreži entropije, Udruga Bijelo val, 2013.

[28] Ž. Paić, Traume razlika, Biblioteka Intermedia, Meandarmedia, 2007.

[29] Ž. Paić, Politika identiteta, Kultura kao nova ideologija, Antibarbarus, 2005.

[30] E. K. Wilber, Brief History of Everything, Gorin, 2005.

[31] Z. Balaž, K. Meštrović, Inteligentni i ekspertni sustavi u elektroenergetici, Tehničko veleučilište u Zagrebu, Elektrotehnički odjel, Manualia Polytechnici Studiorum Zagrabiensis, 2015.

[32] R. Larsen, D. Buss, Personality psychology, Denis Bratko Naklada Slap, 2008.

[33] H. M. McLuhan, Understending Media - Media as Man Extensions, Golden Marketing, 2008

[34] M. Spitzer, Digitalna demencija - Kako mi i naša djeca silazimo s uma, Ljevak d.o.o., 2018.

[35] T. Karsenti, S. Collin, Why are New Teachers Leaving the Profession? Results of a Canada-Wide Survey, Education Faculty, University of Quebec and Montreal, 2013.

[36] N. Carr, Plitko - Što Internet čini našem mozgu, Jesenski i Turk, 2011.

[37] N. Carr, Stakleni kavez, Jesenski i Turk, 2016.

[38] J. Baudrillard, Le Pacte de Lucidité ou L'Intelligence du Mal, Ljevak d.o.o. 2006 ,

[39] J. Baudrillard, Simulakrumi i simulacije - Biblioteka Psefizma, 2001.

[40] Ž. Paić, Posthumano stanje: Kraj čovjeka i mogućnost druge povijesti, Litteris, 2011. 